\title{
Melanin-templated rapid synthesis of silver nanostructures
}

\author{
George Seghal Kiran ${ }^{1}$, Asha Dhasayan², Anuj Nishanth Lipton ${ }^{3}$, Joseph Selvin ${ }^{3 *}$, Mariadhas Valan Arasu ${ }^{4}$ \\ and Naif Abdullah Al-Dhabi ${ }^{4}$
}

\begin{abstract}
Background: As a potent antimicrobial agent, silver nanostructures have been used in nanosensors and nanomaterial-based assays for the detection of food relevant analytes such as organic molecules, aroma, chemical contaminants, gases and food borne pathogens. In addition silver based nanocomposites act as an antimicrobial for food packaging materials. In this prospective, the food grade melanin pigment extracted from sponge associated actinobacterium Nocardiopsis alba MSA10 and melanin mediated synthesis of silver nanostructures were studied. Based on the present findings, antimicrobial nanostructures can be developed against food pathogens for food industrial applications.
\end{abstract}

Results: Briefly, the sponge associated actinobacterium N. alba MSA10 was screened and fermentation conditions were optimized for the production of melanin pigment. The Plackett-Burman design followed by a Box-Behnken design was developed to optimize the concentration of most significant factors for improved melanin yield. The antioxidant potential, reductive capabilities and physiochemical properties of Nocardiopsis melanin was characterized. The optimum production of melanin was attained with $\mathrm{pH} 7.5$, temperature $35^{\circ} \mathrm{C}$, salinity $2.5 \%$, sucrose $25 \mathrm{~g} / \mathrm{L}$ and tyrosine $12.5 \mathrm{~g} / \mathrm{L}$ under submerged fermentation conditions. A highest melanin production of $3.4 \mathrm{mg} / \mathrm{ml}$ was reached with the optimization using Box-Behnken design. The purified melanin showed rapid reduction and stabilization of silver nanostructures. The melanin mediated process produced uniform and stable silver nanostructures with broad spectrum antimicrobial activity against food pathogens.

Conclusions: The melanin pigment produced by N. alba MSA10 can be used for environmentally benign synthesis of silver nanostructures and can be useful for food packaging materials. The characteristics of broad spectrum of activity against food pathogens of silver nanostructures gives an insight for their potential applicability in incorporation of food packaging materials and antimicrobials for stored fruits and foods.

Keywords: Marine Nocardiopsis, Melanin, Optimization, Silver nanostructures, Antimicrobial activity

\section{Background}

Silver particles/nanostructures have been used as an effective antimicrobial agent in food and beverage storage for a long time. Silver containing plastics had been incorporated in refrigerator liners and food storage containers [1-3]. FDA has been approved the use of silver based particles for disinfection purpose for the food contacting materials [4].

Silver based nanomaterials and nanocomposite can be devised for the easiest detection of commonly found

\footnotetext{
* Correspondence: josephselvinss@gmail.com

${ }^{3}$ Department of Microbiology, Pondicherry University, Puducherry 605014, India Full list of author information is available at the end of the article
}

food adulterants, chemical contaminants, allergens and any changes respond to environmental conditions etc. Silver nanoparticles incorporated cellulose pads are used to control the food pathogens from packed beef meat and reduce the microbial count in fresh cut melon [5]. Apart from this, silver nanoparticles slower the ripening times of stored fruits by catalyzing the destruction of ethylene gas and increase the shelf lives of stored fruits [5]. Several studies have demonstrated the efficacy of silver nanoparticles loaded packaging materials in campaigning against microbial growth in foods [5-8]. Nanostructured antimicrobials have a higher surface area-to-volume ratio than their microscale counterpart and their incorporation in food packaging systems are supposed to be particularly

\section{Biomed Central}


efficient in their activities against microbial cells [9]. The development of stable, mono dispersible, metallic silver nanostructures synthesis via reliable green synthesis has been an important aspect of current nanotechnology research. The aggregation of silver nanostructures and the insufficient stability of their dispersions lead to loss of their special nanoscale properties. Researchers employ polymer-assisted fabrication routes and various chemical stabilizing agents (surfactants such as CTAB, SDS etc., and polymers such as PVP) for preventing the selfaggregation of nanostructures [10-12]. The use of chemical compounds is toxic and will reduce the biological applicability. The use of natural products such as biosurfactant, monosaccharides, plant extracts etc. as enhancers and stabilizing agent for silver nanostructures synthesis were extensively studied. The marine glycolipid biosurfactant stabilized silver nanoparticles were synthesized by Brevibacterium casei MSA19 under solid state fermentation using agro-industrial and industrial waste as substrate [13]. Apte et al. [14] studied L-DOPA mediated synthesis of melanin by fungi Yarrowia lipolytica and the induced melanin has been exploited in the synthesis of silver and gold nanostructures. In this study, rapid reliable approach has been developed to produce uniform silver nanostructures by purified melanin from marine Nocardiopsis alba MSA10.

As melanin pigments are used as food colorant and nutritional supplements, which reflects the industrial need to large scale production as natural ingredients. Natural pigment production especially from microorganisms is emerging as an important aspect due to their wide acceptance in various industrial sectors [15] and it replaces the chemically synthesized pigments which cause harmful effects in the natural environment [16]. The microbial pigment, melanin has received considerable attention because of their useful biological activities especially in food and pharmaceutical industries. Melanins are high molecular weight pigments that are produced in microorganisms by oxidative polymerization of phenolic or indolic compounds with free radical generating and scavenging activity [17]. Based on chemical structure, properties and species affiliation, melanins are classified as allo-, pheo-, and eumelanins. The black or brown eumelanins are produced by oxidation of tyrosine through tyrosinase to DOPA (o- dihydroxyphenylalanine) and dopachrome, further the cyclization mediates to form 5,6-dihydroxyindole (DHI) or 5,6-dihydroxyindole-2-carboxylic acid (DHICA) [18]. The yellow-red pheomelanins are synthesized like eumelanins in the first step; the intermediate DOPA undergoes cysteinylation, directly or mediated by glutathione to form various derivatives of benzothiazines [19]. The third types of allomelanins are heterogenous group of polymers synthesized via pentaketide pathway [20]. Brown pigments may also produce from L-tyrosine pathway via accumulation and autooxidation of intermediates of tyrosine catabolism [18]). Microbial melanin has a wide range of applications including photoprotective, radioprotective, immuno-modulating, antimicrobial and antitumour activities [21-23]. Actinobacteria were resilient bacteria found among culturable sponge microbes and are current focus on bioactive leads from marine environment [24]. The sponge associated actinomycetes has wide application as antiviral, antibacterial, antitumour, anti-helminthic, insecticidal, immuno-modulator, immuno-suppressant and food colorants [25]. Melanin producing microorganisms are ubiquitous in nature; however limited literature is available on actinobacterial melanin production at different cultural conditions. Therefore, this study aims to enhance the production of melanin from marine actinobacterium $N$. alba MSA10, by optimizing various cultural and environmental parameters under submerged conditions as well as melanin mediated synthesis of silver nanostructures.

\section{Results}

\section{Screening and identification of melanin producers}

The strain MSA10 was considered as potential melanin producers among the other isolates obtained from the sponge Dendrilla nigra. The MSA10 strain was Gram positive and mycelia appearance under phase contrast microscope, which produce white powdery colonies on the actinomycetes isolation agar. It showed positive results on indole, citrate utilization, urease and triple sugar ion tests and negative results in methyl red, Voges Proskauer and catalase tests. Based on the morphological, biochemical, phylogenetic analysis (UPGMA algorithm) and taxonomic affiliation (RDP-II), the isolate MSA10 was identified as Nocardiopsis alba MSA10. The 16S rRNA sequence was deposited in Genbank with an accession number EU563352. It was found that the isolate MSA10 showed clustering exclusively with pigment producing Streptomyces strain and also an efficient biosurfactant producer [26]. Melanin production by $N$. alba MSA10 was initiated at $72 \mathrm{~h}$ of incubation, the medium changed to light brown, further the color development was increased at 96, 120 and $144 \mathrm{~h}$ to light brown, brown and dark brown respectively. The melanin production was depending on the biomass yield and a highest yield of biomass with melanin was obtained at $144 \mathrm{~h}$ of incubation (Figure 1).

\section{Formulation of fermentation media for melanin production}

It is evident that different media constituents such as carbon, nitrogen, metal ions, and organic solvents and environmental factors such as $\mathrm{pH}$, temperature, and salinity are 


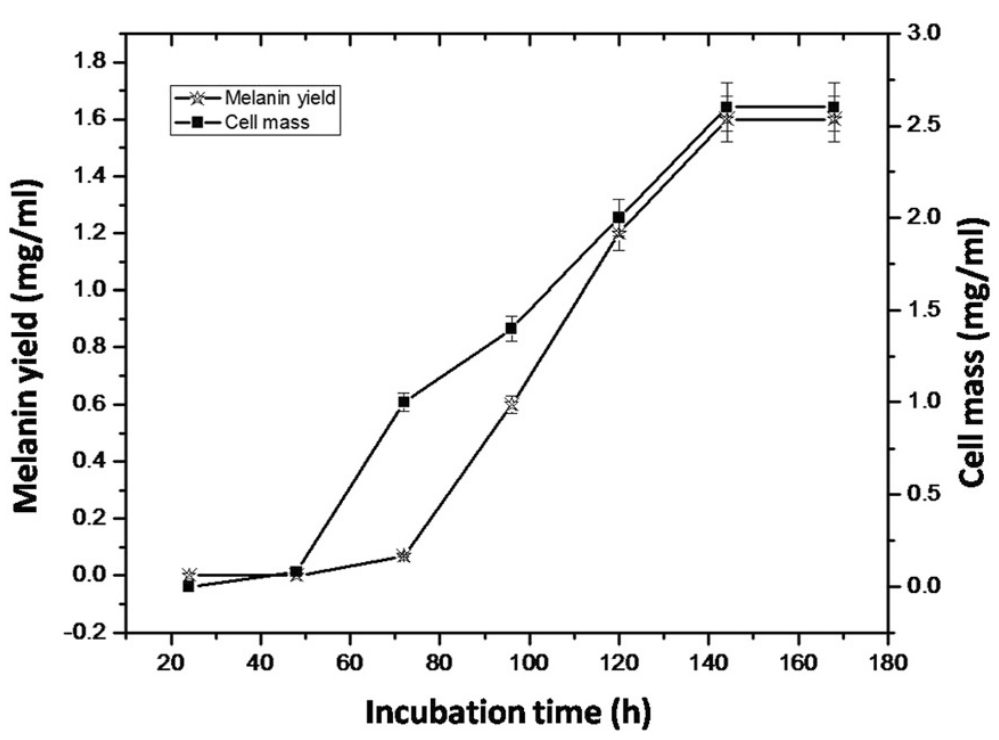

Figure 1 Melanin production rate at different incubation time by Nocardiopsis alba MSA10.

known to play a vital role in the melanin production. The fermentation conditions and media constituents including sucrose, tyrosine, temperature and salinity as most significant variables were optimized for enhanced melanin yield. The correlation between melanin yield and the four critical control factors (variables) were analyzed by Box- Behnken design, the following quadratic model polynomial equation was obtained to explain melanin yield in $\mathrm{mg} / \mathrm{ml}(\mathrm{Y})$.

$$
\begin{aligned}
\mathrm{Y}= & +3.40-0.092 * \mathrm{~A}-0.042 * \mathrm{~B}-0.13 * \mathrm{C}-0.15 \\
& * \mathrm{D}+0.12 * \mathrm{~A} * \mathrm{~B}+0.000 * \mathrm{~A} * \mathrm{C}+0.20 \\
& * \mathrm{~A} * \mathrm{D}-0.100 * \mathrm{~B} * \mathrm{C}-0.10 * \mathrm{~B} * \mathrm{D}-0.30 \\
& * \mathrm{C} * \mathrm{D}-0.67 * \mathrm{~A} 2-0.74 * \mathrm{~B} 2-0.75 \\
& * \mathrm{C} 2-0.53 * \mathrm{D} 2
\end{aligned}
$$

The statistical significance of the equation 1 was checked by F- test and the results of ANOVA are shown in Table 1. The model $\mathrm{F}$ value of 251.68 implies the model is more significant $(<0.0001)$. The coefficient determination $\left(R^{2}\right)$ value was found to be 0.9960 , which implies that the variation of $99.60 \%$ for the melanin yield was attributed to the independent variables and only $0.40 \%$ of the total variation could not be explained by the model. The $\mathrm{R}^{2}$ value found in this study was closer to 1 show that the developed model could effectively increase the melanin production $(3.4 \mathrm{mg} / \mathrm{ml})$.

The 3D response surface plots showed the effect of medium components and fermentation conditions on the production of melanin (Figure 2). The response surface curve was plotted with two factors varied at a time when the other two factors as being remained at a fixed level. Higher melanin yield $(3.4 \mathrm{mg} / \mathrm{ml})$ was obtained with $12.5 \mathrm{~g} / \mathrm{l}$ of tyrosine and $25 \mathrm{~g} / \mathrm{l}$ of sucrose in the medium and maintaining the other parameters such as salinity (2.5\%), $\mathrm{pH}(7.5)$ and temperature $\left(35^{\circ} \mathrm{C}\right)$ as constant (Figure 2). When the $\mathrm{pH}$ was below $7.5(6.0-6.5)$ and the temperature above $35^{\circ} \mathrm{C}$, the growth of $N$. alba MSA10 as well as melanin production has declined drastically. The pigment production consequently increased

\begin{tabular}{|c|c|c|c|c|c|}
\hline Source & Sum of squares & df & Mean square & F value & $\begin{array}{l}\text { p-value } \\
\text { prob > F }\end{array}$ \\
\hline Model & 9.02 & 14 & 0.64 & 251.68 & $<0.0001^{* *}$ \\
\hline A-Sucrose & 0.10 & 1 & 0.10 & 39.40 & $<0.0001^{* *}$ \\
\hline B-Tyrosine & 0.021 & 1 & 0.021 & 8.14 & $0.0128^{*}$ \\
\hline C-Temperature & 0.21 & 1 & 0.21 & 83.35 & $<0.0001^{* *}$ \\
\hline D-Salinity & 0.27 & 1 & 0.27 & 105.49 & $<0.0001^{* *}$ \\
\hline$A B$ & 0.063 & 1 & 0.063 & 24.42 & $0.0002^{*}$ \\
\hline$A C$ & 0.000 & 1 & 0.000 & 0.000 & 1.0000 \\
\hline$A D$ & 0.16 & 1 & 0.16 & 62.51 & $<0.0001^{* *}$ \\
\hline$B C$ & 0.040 & 1 & 0.040 & 15.63 & $0.0014^{*}$ \\
\hline$B D$ & 0.040 & 1 & 0.040 & 15.63 & $0.0014^{*}$ \\
\hline$C D$ & 0.36 & 1 & 0.36 & 140.65 & $<0.0001^{* *}$ \\
\hline$A^{2}$ & 2.88 & 1 & 2.88 & 1126.34 & $<0.0001^{* *}$ \\
\hline$B^{2}$ & 3.57 & 1 & 3.57 & 1394.02 & $<0.0001^{* *}$ \\
\hline$C^{2}$ & 3.69 & 1 & 3.69 & 1441.40 & $<0.0001^{* *}$ \\
\hline$D^{2}$ & 1.82 & 1 & 1.82 & 709.64 & $<0.0001^{* *}$ \\
\hline
\end{tabular}
with increasing the temperature up to $35^{\circ} \mathrm{C}$, but the growth of $N$. alba MSA10 was found optimum at the

Table 1 ANOVA for response surface quadratic model of melanin production

${ }^{* *}$ More significant, ${ }^{*}$ Significant; R-Squared 0.9960, Adj R-Squared 0.9921 


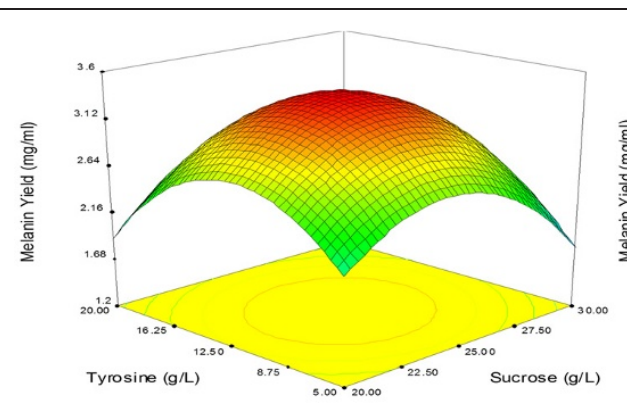

(A)

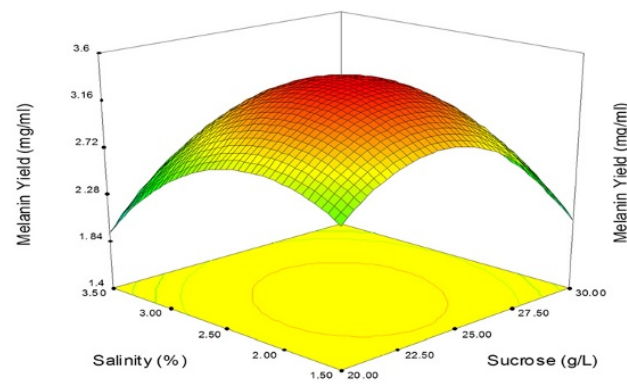

(C)

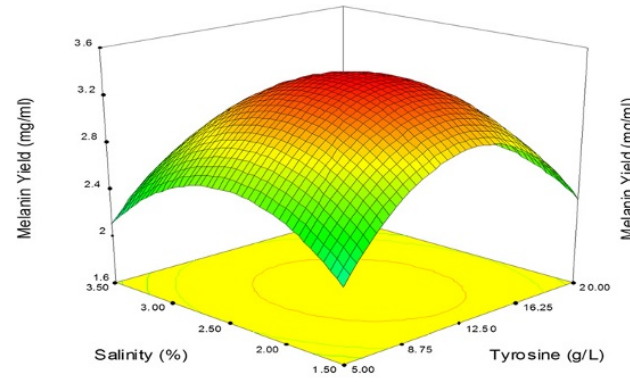

(E)

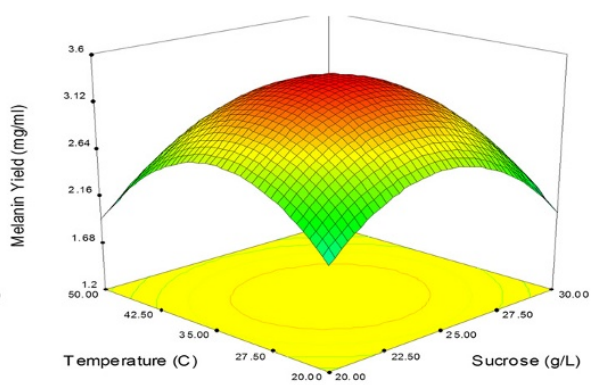

(B)

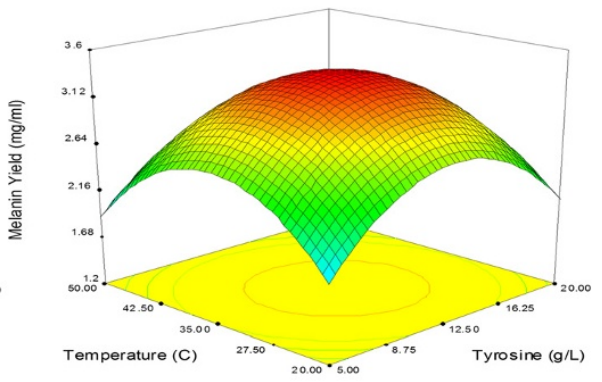

(D)

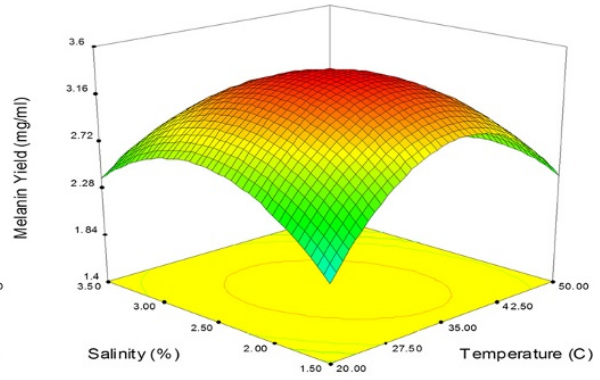

(F)

Figure 2 The response surface plot shows the most significant variables interaction on melanin production. (A) tyrosine and sucrose, (B) temperature and sucrose, (C) salinity and sucrose, (D) temperature and tyrosine, (E) salinity and tyrosine, and (F) salinity and temperature.

temperature of $28-30^{\circ} \mathrm{C}$. It was found that at $\mathrm{pH} 7.5$, the growth of $N$. alba MSA10 and melanin production was found to be linear. This suggests that the near neutral $\mathrm{pH}$ was optimum for higher biomass and melanin production.

\section{Lights on melanin production}

Light is considered as important environmental parameters for melanin production. Literature evidenced that pigments absorbed light at a particular wavelength and emits different colors. In this study, the various light sources such as green, red and yellow light on enhanced melanin production were investigated. It was found that the green light excitation had resulted in highest melanin production with the formation of dark brown color. Considerable pigment production was observed in red light and there is no pigment production in yellow light source in the culture plate, but slight production was observed in the fermentation medium at $144 \mathrm{~h}$ of incubation (Figure 3).

\section{Characterization of melanin pigment}

The chromatogram of violet color spot on TLC plate showed an $R_{f}$ value of 0.74 related to melanin pigment. A strong peak at $220 \mathrm{~nm}$ was obtained for UV- visible spectrum of Nocardiopsis melanin (data not shown). The colorimeter L* (lightness ranges from 0-100 (dark - light) $\mathrm{a}^{*}$ (red- green) and $\mathrm{b}^{*}$ (yellow-blue) values of melanin reflects the dark brown color. The $L^{*}, a^{*}$ and $b^{*}$ values of melanin was found to be $2.74,0.22$ and 0.96 respectively. The low lightness value shows the dark color pigment. The values of $\mathrm{a}^{*}(\mathrm{R}-\mathrm{G})$ and $\mathrm{b}^{*}$ (Y-B) represents the Nocardiopsis melanin pigment as a dark brown color. The FT-IR spectrum of column purified melanin showed the absorbance bands at 1118, 1385, $2077 \mathrm{~cm}^{-1}$ and a strong band at $3397,1638,674 \mathrm{~cm}^{-1}$. The intense broad band at 

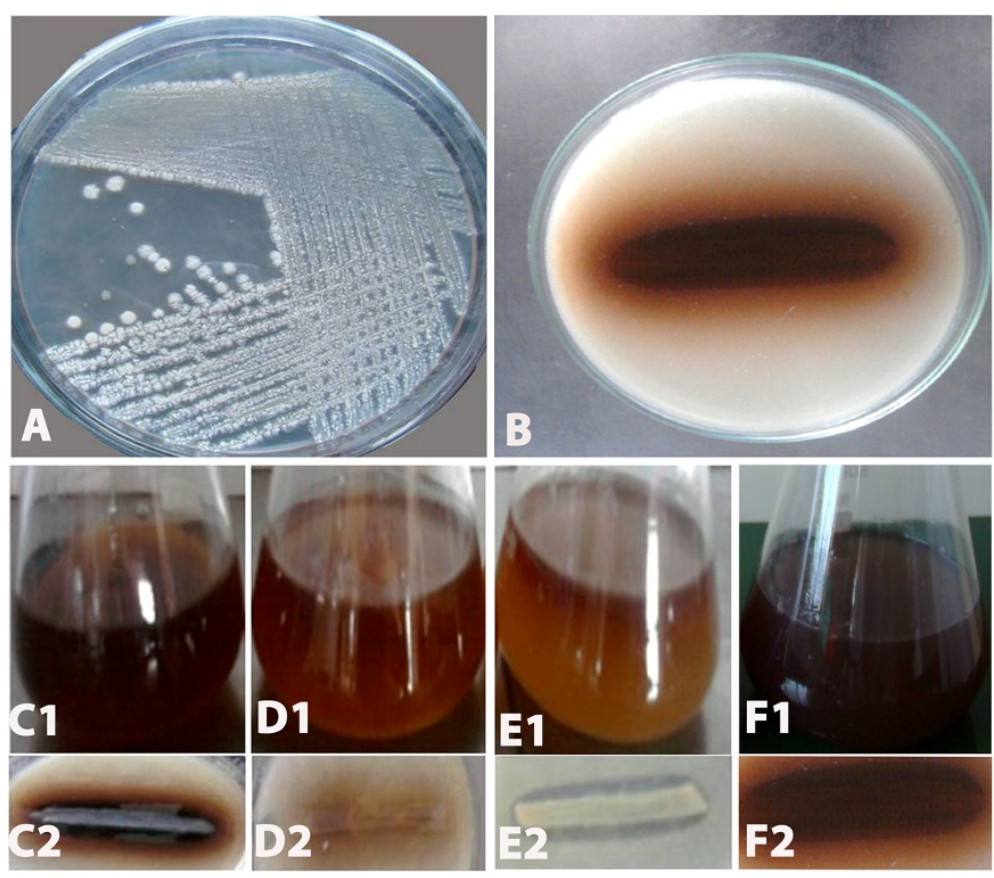

Figure 3 Effects of light source on melanin production. Growth of N. alba MSA 10 on Actinomycetes isolation agar medium (A), Melanin production on tyrosine (1\%) agar medium (B), Green light source on melanin production in tyrosine broth (C1) and tyrosine agar medium (C2), which produces dark brown pigment. Red light source produces brown pigment, tyrosine broth (D1) and tyrosine agar (D2). Yellow light shows light brown pigment production on tyrosine broth (E1) at $144 \mathrm{~h}$ incubation, but no pigment production in tyrosine agar medium (E2). The pigment production at normal light source on tyrosine broth (F1) and tyrosine agar medium (F2) produces dark brown pigment.

$3397 \mathrm{~cm}^{-1}$ corresponds to the $\mathrm{OH}$ groups of polymeric structure, the band at 1638 and 1118 associated with primary amine $\mathrm{NH}$ and primary amine $\mathrm{CN}$ stretch vibrations of melanin respectively. The band at $1385 \mathrm{~cm}^{-1}$ is assigned to methylene scissoring of $\mathrm{C}-\mathrm{H}$ groups and the band around 2077 arises from the carbonyl stretching vibrations. The TLC chromatogram and FT-IR spectrum analysis confirmed the melanin pigment produced by $N$. alba MSA10.

\section{Physico chemical properties of purified melanin}

The Nocardiopsis melanin was found to be dissolving immediately in alkaline water and hexane when compared to water at room temperature. A precipitation was formed when the melanin was allowed to dissolve in ethanol, methanol and $\mathrm{HCl}$. It remains insoluble in ether, chloroform and ethyl acetate. Nocardiopsis melanin was stable at the range of temperatures $\left(20-100^{\circ} \mathrm{C}\right)$ even for $3 \mathrm{~h}$ (Figure 4) and light sources including UV, natural sun light and complete darkness. The stability of different $\mathrm{pH}(3-12)$ of melanin tested had showed slight variation of absorption spectrum scanned at 190-220 nm (data not shown). The strong peak at 215 was observed (peak value 3.9) in the alkaline $\mathrm{pH}$ (9, 10 and 12), which indicates the relative stability of melanin in alkaline conditions when compared to neutral and acidic conditions. Similar water solubility nature of melanin has been reported in a mutant strain of Bacillus thuringiensis [27]. The other physico chemical properties are similar to melanin obtained from Osmanthus fragrans seeds [28].

\section{Antioxidant activity and reducing power of melanin}

The antioxidant assay is based on the reduction of Mo (VI) to Mo (V) by melanin with the formation of a green phospho molybdenum complex at different temperatures. Even though the green - complex formation takes place at room temperature, the formation of maximum phospho molybdenum complex increases with the increasing temperature of 90 and $180^{\circ} \mathrm{C}$. Figure 5 shows the antioxidant property exhibited by Nocardiopsis melanin. Similar results were obtained with the melanin from berry of Cinnamomum burmannii and Osmanthus fragrans [29]. The reducing capabilities of Nocardiopsis melanin from $\mathrm{Fe}^{3+}$ to $\mathrm{Fe}^{2+}$ was clearly investigated with the standard BHT (Figure 6) and the results evidenced and validated the antioxidant property. Presence of antioxidant substances enhance the reduction of $\mathrm{Fe}^{3+} /$ Ferricyanide complex to the $\mathrm{Fe}^{2+}$ form, which can be monitored at $700 \mathrm{~nm}[30]$. 


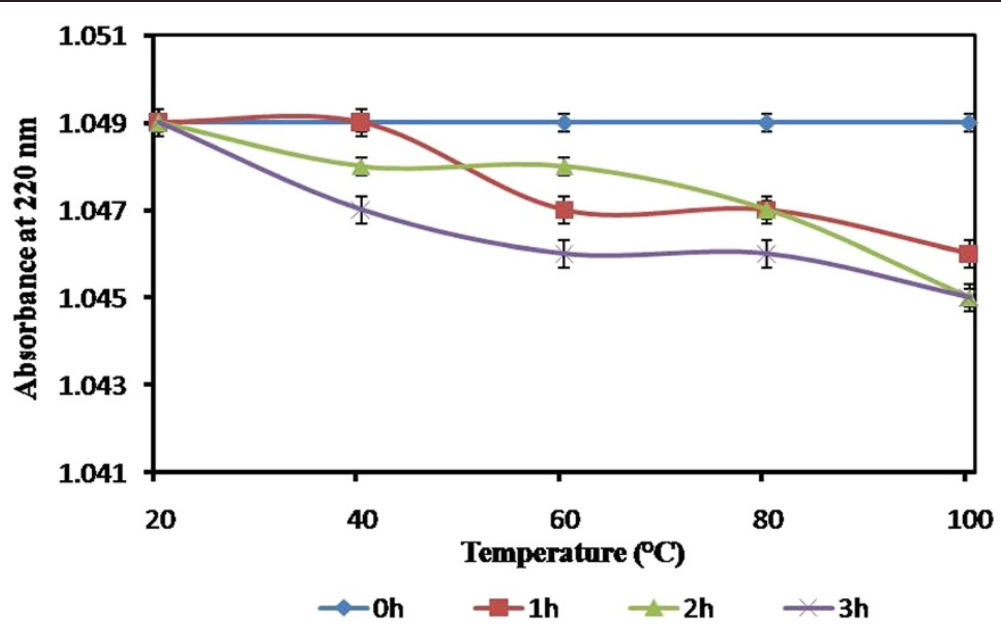

Figure 4 Temperature stability of melanin produced by Nocardiopsis alba MSA 10 with different incubation times measured by UV absorbance at $220 \mathrm{~nm}$ (mean \pm S.D., $\mathrm{n}=3$ ).

Melanin mediated synthesis of silver nanostructures and antimicrobial assay

The synthesis of melanin mediated silver nanostructures was confirmed by the appearance of strong peaks in the UV- visible spectra at 420-460 $\mathrm{nm}$. With the increase in temperature $\left(100^{\circ} \mathrm{C}\right)$ stable and rapid synthesis of same sized particles takes place (Figures 7A and 8B). The synthesis pattern of UV- Visible spectrum at different temperature profile is depicted in Figure 7B. It is evident from the UV - absorbance spectrum that the temperature at $100^{\circ} \mathrm{C}$ shows effective synthesis. It is noticeable that the temperature stability of Nocardiopsis melanin tested before showed stability at $100^{\circ} \mathrm{C}$ over $3 \mathrm{~h}$. The antioxidant and reductive capabilities of the melanin compound enhances the rapid synthesis of silver nanostructures without adding any capping agent. Thus, melanin acts as both reducing and capping agent of silver nano- sized structures synthesis. The synthesis at various time interval shows that increasing incubation time at $30 \mathrm{~min}$ gives more stable particles when compared to 0, 10 and 20 min (Figure 7B). The FT-IR spectrum of melanin mediated silver nanostructures shows (Figure 9) characteristics absorbance bands of 3466, 3400, 2083, 1638, 1420, 1370, 1234, 1099 and $664 \mathrm{~cm}^{-1}$ respectively. The shift in the bands at 1118 of pure Nocardiopsis melanin towards their lower frequency to 1099 is attributed to the binding of primary amine $(\mathrm{N}-\mathrm{H})$ to the silver ions. The shifting of symmetrical stretch of carboxylate group at 1385 to 1370 and 1234 clearly shows the reaction between silver particles to carboxylate group of melanin. The appearance of new band at 3466, shifting of band at $3397-3400$ and $2077-2083 \mathrm{~cm}^{-1}$ were suspected to cause heating of melanin with silver nitrate solution. The TEM results (Figure 8 ) showed that all synthesized particles were

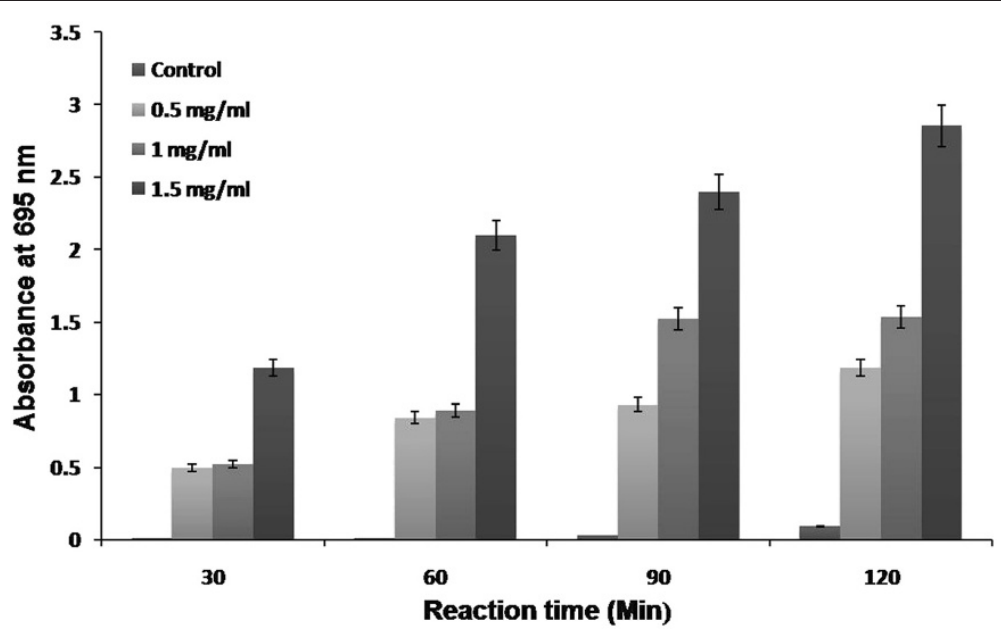

Figure 5 Antioxidant activity in different concentration of Nocardiopsis melanin. 


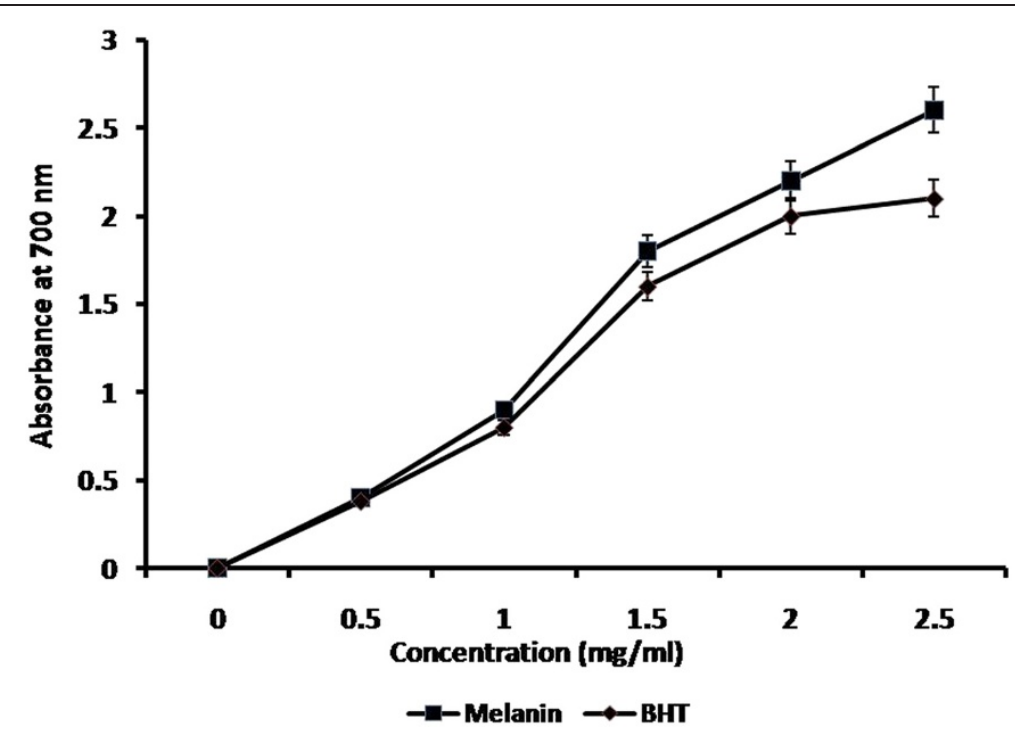

Figure 6 Reductive capabilities in various concentrations of Nocardiopsis melanin and a standard BHT.

spherical in shape and found to be well dispersed in aqueous medium. The particle sizes ranging from $20-50 \mathrm{~nm}$ were formed. The melanin-silver nanoparticles showed (Figure 10) antimicrobial activity against all food pathogens tested but the highest activity was found against $B$. cereus $\left(140 \mathrm{~mm}^{2}\right)$ and P. fragi and E. coli $\left(120 \mathrm{~mm}^{2}\right.$ respectively).

\section{Discussion}

Industrial production of colorants from microorganisms are more suitable due to factors such as ease of availability, culturing, higher production of pigments and the microbes' potential to be genetically manipulated. Isolation of new strain is still of particular interest because of the
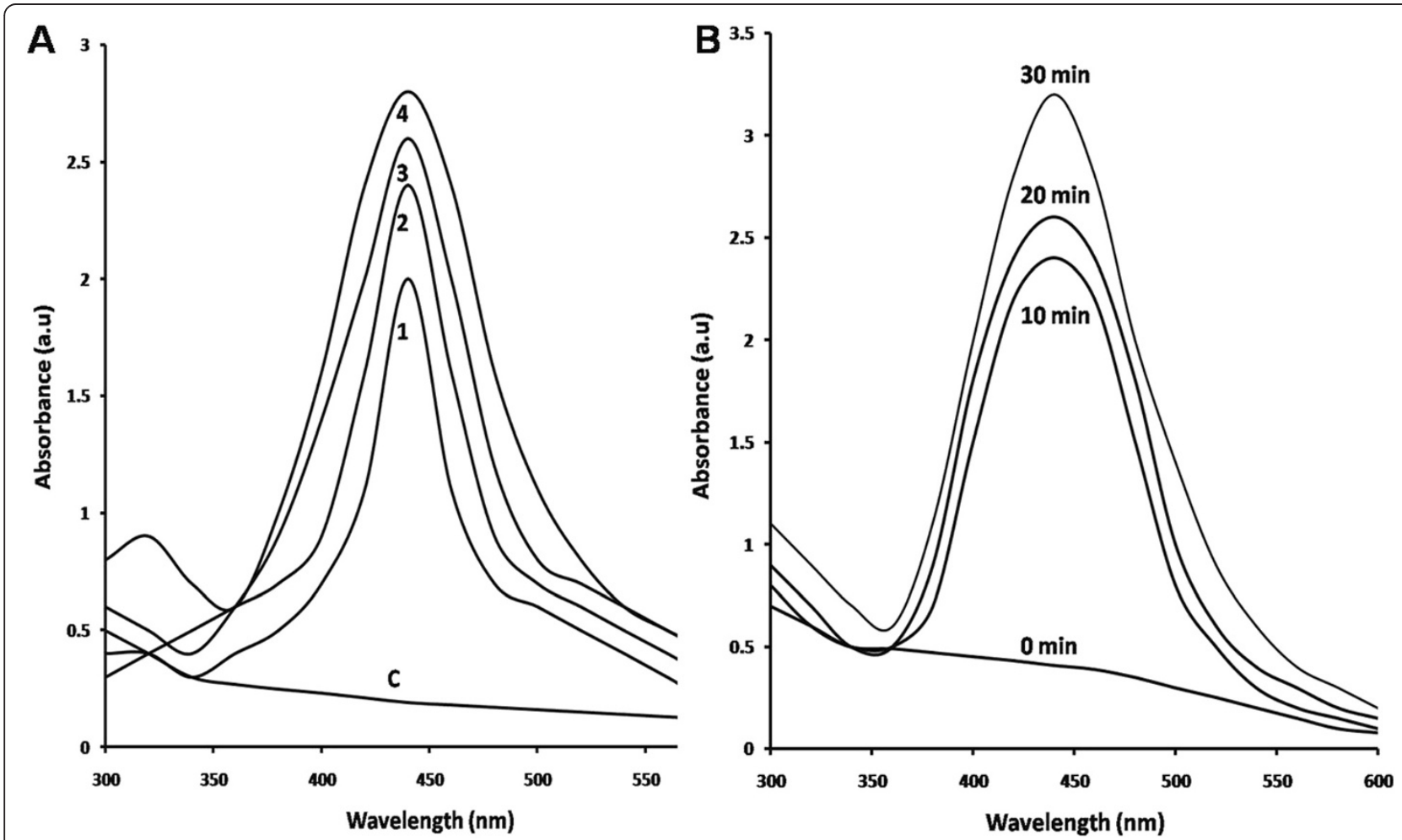

Figure 7 UV absorption spectra of synthesized silver nanostructures. (A) At different temperatures. $\mathrm{C}$ - Control ( $\mathrm{AgNO}_{3}$ solution (1 $\left.\mathrm{mM}\right)$, $1-40^{\circ} \mathrm{C}, 2-60^{\circ} \mathrm{C}, 3-80^{\circ} \mathrm{C}$ and $4-100^{\circ} \mathrm{C}$ (B) At different time intervals. 


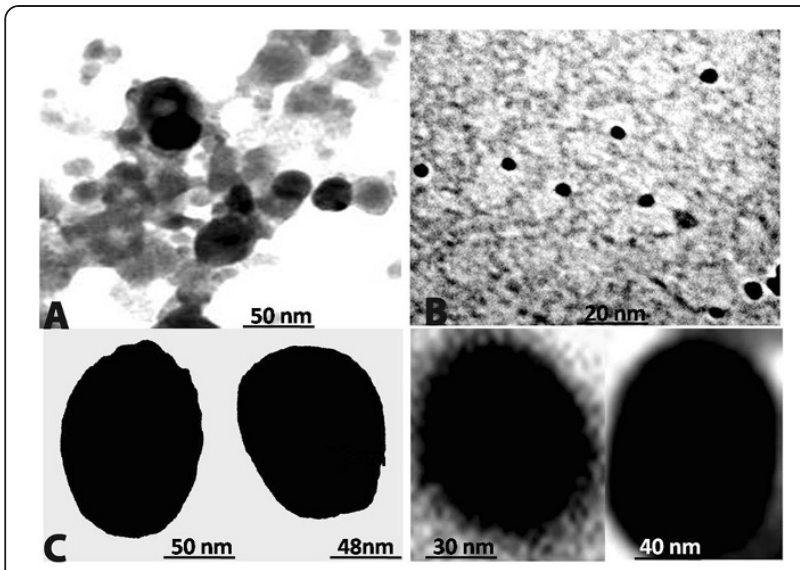

Figure 8 TEM images of synthesized silver nanostructures. (A) Silver nanostructures, (B) nanostructure synthesis at $100^{\circ} \mathrm{C}$ and (C) different sizes of synthesized silver nanostructures.

necessity to obtain microorganisms with suitable characteristics for submerged cultivation. Recently, sponge associated marine bacteria have been considered as a potential source of food-grade pigments [31].

The production of melanin by $N$. alba MSA10 was attributed to the supplement of tyrosine on the production medium via tyrosinase enzyme. The formation of dopachrome (red coloration) and the OD of 0.148 in tyrosinase assay were confirmed by tyrosinase activity of $N$. alba MSA10. The strain $N$. alba MSA10 utilized up to $12.5 \mathrm{~g} / \mathrm{l}$ of tyrosine but on further addition up to $20 \mathrm{~g} / \mathrm{l}$, the melanin production rate gets declined. This shows that the strain N. alba MSA10 had produced melanin by the mediation of tyrosinase. According to Williams [32], about one third of the taxa of the genus Streptomyces produce melanin. In strains including Streptomyces antibioticus, S. glaucescens and S. lavendulae, the tyrosinase gene for melanin production have been cloned, sequenced and recombinantly produced the protein which has sequence similarity to mammalian tyrosinase [33,34]. Melanin like pigments formed from L-tyrosine with different melanogenic pathway in S. avermitilis [35], Xanthomonas campestris [36], Shewanella colwelliana [37] and Vibrio cholerae [38] has been well deliberated.

Sucrose $(25 \mathrm{~g} / \mathrm{l})$ as carbon source increased the melanin production up to $3.4 \mathrm{mg} / \mathrm{ml}$ significantly followed by glucose as alternative carbon source in $N$. alba MSA 10. Till date, there is no report on the production of melanin from sucrose as a sole carbon source. The red pigment produced by Paecilomyces sinclarii showed maximum mycelial growth in sucrose as carbon source, even though the highest pigment production has been attributed in soluble starch medium [39].

Stimulatory effects of various nitrogen sources including peptone, beef extract, yeast extract, urea and ammonium nitrate were tested by Placket-Burman experimental design, and the significant effect was found in case of beef extract and ammonium nitrate on melanin production. This shows that only trace amount of nitrogen source was utilized by $N$. alba MSA10 for melanin production, as the amino acid tyrosine mediates the melanin synthesis pathway. The strain MSA10 had utilized considerable level of nitrogen sources for their growth and mycelial development; however melanin production gets enhanced with the addition of tyrosine in the production medium. The strain grows optimum up to $3.5 \%$ of $\mathrm{NaCl}$ and the highest melanin production $(3.4 \mathrm{mg} / \mathrm{ml})$ has obtained at $2.5 \%$ of salinity. Further increasing salinity, the melanin

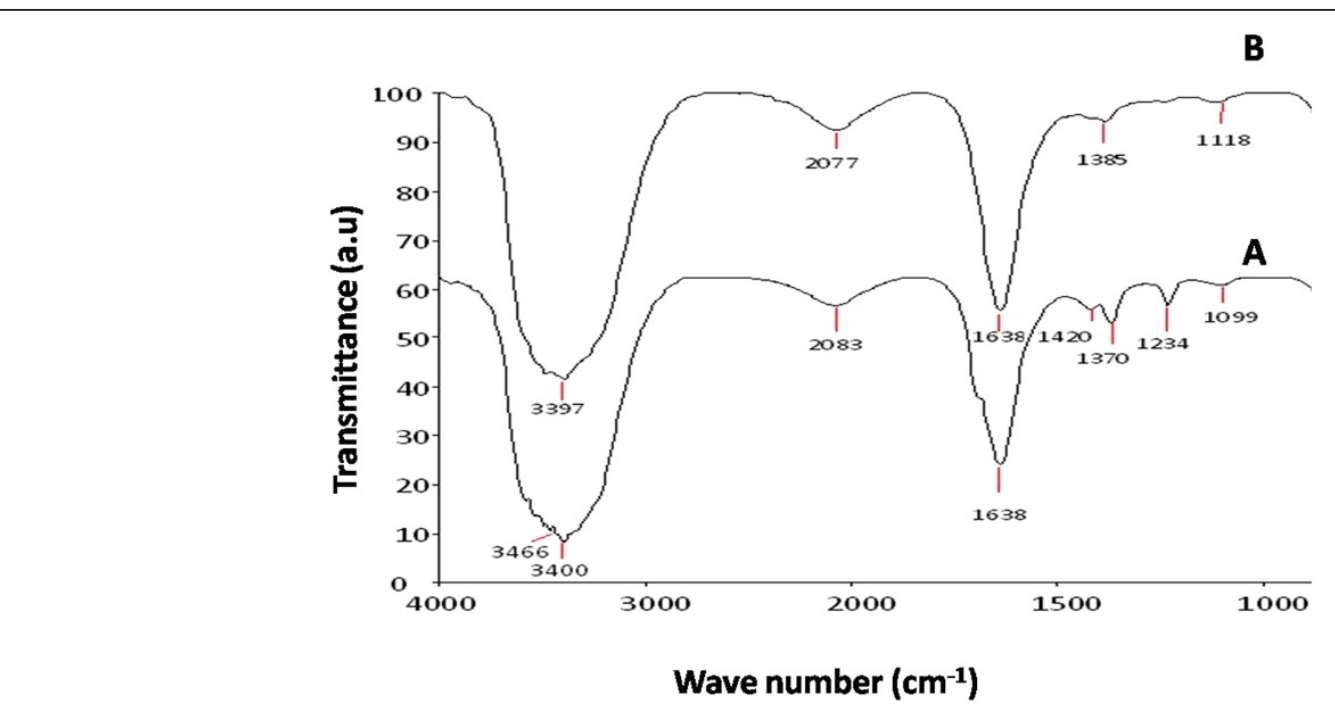

Figure 9 FTIR spectra of synthesized silver nanostructures. (A) Silver nanostructures, and (B) pure melanin. 


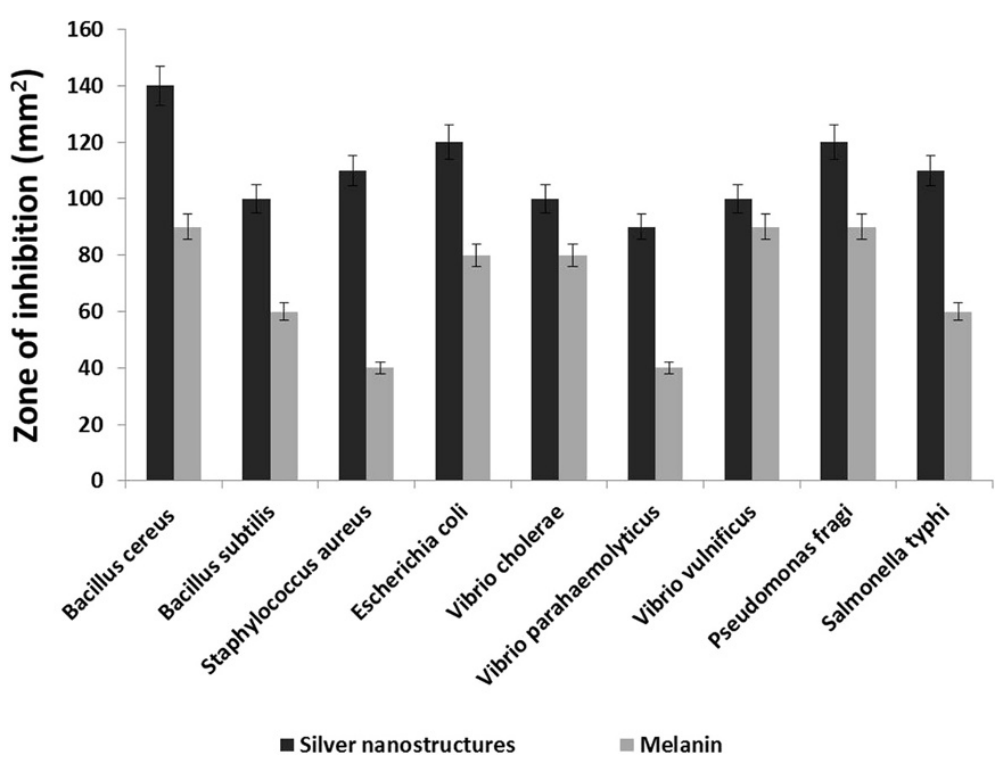

Figure 10 Antimicrobial assay of melanin and melanin- mediated synthesis of silver nanostructures.

production was found to be decreased. Melanin production by $N$. alba MSA10 was highest at $35^{\circ} \mathrm{C}$ and $\mathrm{pH} 7.5$. The highest yield of pigment from Monascus was reported at $30^{\circ} \mathrm{C}$ [40]. The initial $\mathrm{pH}$ at 6 and temperature of $32^{\circ} \mathrm{C}$ increased the pigment production by Monascus sp. [41].

The pigment production by Monascus purpureus with various light sources was well recognized by Babitha et al.[42] and this finding described that red light have little effect on growth and pigment production when compared to green and blue light sources which probably inhibits the pigment production, even though there is significant increase in biomass under green light. Despite the importance of influence of light on pigment production as investigated on Monascus purpureus [42], much has not yet been determined on actinomycetes melanin. Therefore, the strain N. alba MSA10 would be the first record among the actinomycetes produced melanin under illumination of the green light source.

The predicted melanin yield was found to be closer to actual melanin yield and the production rate was increased one fold over the wild strain $N$. alba MSA10. It reveals that the generated Box-Behnken design showed the interaction and actual relationships between the critical control factors. The RSM-based experiments showed that $N$. alba MSA10 has higher melanin $(3.4 \mathrm{mg} / \mathrm{ml})$ productivity potential.

The FT-IR absorbance band of Nocardiopsis melanin ranging from $3400 \mathrm{~cm}^{-1}$ to $674 \mathrm{~cm}^{-1}$ had high degree of similarity to the BC58 melanin, standard melanin sigma [43] and synthetic pyomelanin, pyomelanin extracted from Aspergillus fumigatus [44]. The shifting of band related to primary amine $(\mathrm{N}-\mathrm{H})$, carboxylate group and
C-O stretch vibration clearly evidenced that Nocardiopsis melanin reduces silver nitrate and the same time it stabilizes the synthesized silver nanostructures. The stability of melanin mediated silver nanostructures were determined by synthesized particles which was allowed to stands for 3 months at room temperature. It was found that the color intensity of silver particles increased with aging and no aggregation was observed in duration of 3 months. The free amine or carboxylate group of proteins can bind with silver particles [45]. The interaction of melanin with metal ions, protein [46] and double stranded DNA [47] was extensively studied.

The melanin mediated silver nanostructures found to be most effective on food pathogens such as $B$. cereus, $P$. fragi and $E$. coli. Thereby, the incorporation of melanin mediated synthesized silver nanostructures in food packaging materials can effectively inhibit the growth of food pathogens and increase the shelf life of packed food products. Nanomaterials are being explored for their promising role in food industry such as providing longer shelf-life for foods, better barrier properties, improved heat resistance and temperature control, and antimicrobial and fungal protections [48]. Silver nanoparticles that act as antibacterial agents or nanoclay coatings are currently used in food packaging [49].

The future studies can be focused on the rapid formation of different shape of silver nanostructures under optimal conditions with melanin as reducing and capping agent. The size and shape based silver nanostructures has many positive attributes such as good conductivity, chemical stability, catalytic and antimicrobial activity that make them suitable for many practical food 
packaging applications. The melanin mediated silver nanostructures can be incorporated in food packaging materials. The efficacy of melanin-silver nano-conjugates on the shelf life of packed food products is needs to be investigated.

\section{Conclusion}

The melanin pigment has been successfully purified and characterized from $N$. alba MSA10. The cultural conditions and environmental factors for enhanced yield of melanin were optimized through RSM- Box- Behnken design. The purified melanin has been used to synthesize and stabilizes the silver nanostructures in vitro. The antioxidant activity, reducing power and physicochemical properties of Nocardiopsis melanin was well characterized. The antioxidant, antimicrobial and natural coloring potential of Nocardiopsis melanin can be used as food additives, which significantly reduces the usage of artificial or synthetic colorants and antioxidants. The UV protective roles, withstanding higher temperatures, stability in alkaline conditions and water solubility nature of Nocardiopsis melanin increased their application in food, cosmetics and biomedical industries. Thus, the synthesis and stabilization of silver nanostructures by Nocardiopsis melanin demonstrates the metal interacting nature of pigment. Furthermore the antibacterial properties against food pathogens would facilitate its applicability in food processing and food packaging industries.

\section{Methods}

\section{Isolation, screening and identification of melanin} producing marine actinobacterium

The marine actinobacteria were isolated from marine sponge Dendrilla nigra as described by Selvin et al. [50]. The isolated actinobacteria were screened for melanin production on tyrosine agar medium (g/l): (peptone $5 \mathrm{~g}$, sodium chloride $20 \mathrm{~g}$, Beef extract $1.5 \mathrm{~g}$, yeast extract $1.5 \mathrm{~g}$, tyrosine $10 \mathrm{~g}$, agar $20 \mathrm{~g}$ and $\mathrm{pH} 7.3$ ) and were incubated at $30-35^{\circ} \mathrm{C}$ for $6-7$ days. The pigment production was confirmed by the formation of a brownish color around the colonies. The melanin producer strains were identified based on morphological, biochemical and phylogenetic analysis [50].

\section{Fermentation by shake flask culture}

The melanin production was carried out in five sets of $250 \mathrm{ml}$ Erlenmeyer flasks under shake flask culture containing $100 \mathrm{ml}$ of tyrosine medium. The culture flasks were incubated at $35^{\circ} \mathrm{C}$ for 7 days on a rotary shaker (Oasis) at $200 \mathrm{rpm}$. Samples were removed after initial color change periodically for biomass and melanin yield determination. The biomass yield was estimated by washing the cells with phosphate buffered saline $(\mathrm{g} / \mathrm{l})$ $\left(\mathrm{NaCl} 8 \mathrm{~g}, \mathrm{KCl} 0.20\right.$ g, $\mathrm{Na}_{2} \mathrm{HPO}_{4} 1.44 \mathrm{~g}, \mathrm{KH}_{2} \mathrm{PO}_{4} 0.24 \mathrm{~g}$,
$\mathrm{pH}$ 7.4) and dried at $50-60^{\circ} \mathrm{C}$ for $2 \mathrm{~h}$. The melanin supernatant was first adjusted to $\mathrm{pH} 9$ with $10 \mathrm{~N} \mathrm{NaOH}$ to ensure polymerization and then adjusted to $\mathrm{pH} 3$ with $5 \mathrm{~N} \mathrm{HCl}$ to precipitate melanin. The precipitated melanin was centrifuged at 10,000 rpm for $15 \mathrm{~min}$ (Eppendorf), washed thrice with deionized water and lyophilized for dry weight determination.

\section{Formulation of fermentation media for melanin production}

To formulate the media with various concentrations of media constituents on melanin production by MSA10, different carbon, nitrogen sources, metal ions and organic solvents were used. The carbon sources used in this study include $20 \mathrm{~g} / \mathrm{L}$ of glucose, dextrose, sucrose, mannitol and galactose. The organic nitrogen sources include $15 \mathrm{~g} / \mathrm{L}$ of peptone, yeast extract, beef extract, and inorganic nitrogen sources of urea and ammonium nitrate are at the concentration of $100 \mathrm{mg} / \mathrm{L}$. The $\mathrm{pH}$ of the melanin pigment production was studied using shake flask cultures at different initial values of $\mathrm{pH}(4-10)$. The effect of temperature on pigment production was determined with different incubation temperatures $\left(25-60^{\circ} \mathrm{C}\right)$. The $\mathrm{NaCl}$ requirement for pigment production was optimized with 0.5 to $3.5 \% \mathrm{NaCl}$ supplementation. Different metal ions such as $\mathrm{CuSO}_{4}, \mathrm{FeSO}_{4}, \mathrm{MgSO}_{4}, \mathrm{MnCl}_{2}$ and $\mathrm{MnSO}_{4}$ were added in tyrosine broth at $100 \mathrm{mg} / \mathrm{L}$ concentration to determine the effect of metal ions.

\section{Experimental design and statistical analysis}

For all experiments, fermentation was conducted in $500 \mathrm{ml}$ of Erlenmeyer flasks containing different media constituents on melanin production. All experiments were carried out in triplicate and the final melanin yield was taken as the response (y). The Box-Behnken experimental design with four variables (A, B, C and D) such as sucrose, tyrosine, temperature and salinity respectively and three levels high (+), middle (0), and a low (-) was employed to optimize the fermentation conditions and thereby to obtain maximum melanin yield. The experimental design with four variables is summarized in Table 2. Based on Placket-Burman experimental design, the most significant variables sucrose, tyrosine, temperature and salinity were identified from the 11 variables analyzed such as glucose, sucrose, yeast extract, mannitol, tyrosine, ammonium nitrate, ferrous sulphate, $\mathrm{pH}$, temperature, salinity and inoculums size (data not shown). The experimental data was analyzed using the software Design expert 8.0.4.1 trial version (Stat-Ease, Inc, USA).

\section{Light source on melanin production}

The effect of light on melanin production by MSA 10 was studied by passing different wavelengths of light, red (620 $750 \mathrm{~nm})$, blue (450-475 nm), green $(495-570 \mathrm{~nm})$ on 
Table 2 Box - Behnken experimental design with four independent variables (coded values) and the melanin production rate

\begin{tabular}{|c|c|c|c|c|c|c|}
\hline \multirow[t]{2}{*}{ Run } & \multirow[t]{2}{*}{ A } & \multirow[t]{2}{*}{ B } & \multirow[t]{2}{*}{$C$} & \multirow[t]{2}{*}{ D } & \multicolumn{2}{|c|}{ Melanin yield (mg/ml) } \\
\hline & & & & & Actual value & Predicted value \\
\hline 1 & 0 & -1 & 1 & 0 & 1.90 & 1.94 \\
\hline 2 & 1 & 0 & 0 & -1 & 2.00 & 1.98 \\
\hline 3 & -1 & 0 & 0 & 1 & 2.00 & 2.06 \\
\hline 4 & 0 & 0 & 1 & -1 & 2.40 & 2.34 \\
\hline 5 & 0 & 1 & -1 & 0 & 2.10 & 2.12 \\
\hline 6 & 1 & -1 & 0 & 0 & 1.80 & 1.82 \\
\hline 7 & -1 & -1 & 0 & 0 & 2.20 & 2.25 \\
\hline 8 & 0 & -1 & -1 & 0 & 2.00 & 1.98 \\
\hline 9 & -1 & 1 & 0 & 0 & 1.90 & 1.91 \\
\hline 10 & 0 & 1 & 0 & -1 & 2.40 & 2.43 \\
\hline 11 & 0 & 1 & 0 & 1 & 1.80 & 2.40 \\
\hline 12 & -1 & 0 & -1 & 0 & 2.20 & 2.16 \\
\hline 13 & 1 & 1 & 0 & 0 & 2.00 & 1.96 \\
\hline 14 & 0 & 0 & 0 & 0 & 3.40 & 3.40 \\
\hline 15 & 0 & 0 & 1 & 1 & 1.50 & 1.53 \\
\hline 16 & -1 & 0 & 1 & 0 & 2.00 & 1.95 \\
\hline 17 & 0 & 0 & -1 & 1 & 2.40 & 2.43 \\
\hline 18 & 0 & -1 & 0 & 1 & 2.10 & 2.14 \\
\hline 19 & 0 & 1 & 1 & 0 & 1.60 & 1.63 \\
\hline 20 & -1 & 0 & 0 & -1 & 2.60 & 2.65 \\
\hline 21 & 0 & 0 & 0 & 0 & 3.40 & 3.40 \\
\hline 22 & 0 & 0 & 0 & 0 & 3.40 & 3.40 \\
\hline 23 & 0 & 0 & 0 & 0 & 3.40 & 3.40 \\
\hline 24 & 1 & 0 & 0 & 1 & 2.20 & 2.16 \\
\hline 25 & 0 & -1 & 0 & -1 & 2.30 & 2.22 \\
\hline 26 & 0 & 0 & 0 & 0 & 3.40 & 3.40 \\
\hline 27 & 0 & 0 & -1 & -1 & 2.10 & 2.10 \\
\hline 28 & 1 & 0 & -1 & 0 & 2.00 & 2.02 \\
\hline 29 & 1 & 0 & 1 & 0 & 1.80 & 1.75 \\
\hline
\end{tabular}

A: Sucrose $-1(20 \mathrm{~g} / \mathrm{l}), 0(25 \mathrm{~g} / \mathrm{l}),+1(30 \mathrm{~g} / \mathrm{l})$; B: Tyrosine, $-1(5 \mathrm{~g} / \mathrm{l}), 0(12.5 \mathrm{~g} / \mathrm{l}),+1$ $(20 \mathrm{~g} / \mathrm{l})$; C: Temperature, $-1\left(20^{\circ} \mathrm{C}\right), 0\left(35^{\circ} \mathrm{C}\right),+1\left(50^{\circ} \mathrm{C}\right)$; D: Salinity, $-1(1.5 \%)$, $0(2.5 \%),+1(3.5 \%)$.

fermentation medium. The culture flasks were exposed to the light intensity of $32 \mathrm{~W} \mathrm{~m}^{-2}$ for 7 days.

\section{Assay for tyrosinase activity}

Tyrosinase activity was assessed by growing the MSA10 isolates in to glutamate medium [51] and $2 \mathrm{ml}$ of culture supernatant mixed with $2 \mathrm{ml}$ of $0.1 \mathrm{M}$ phosphate buffer (pH 5.9), finally $1 \mathrm{ml}$ DOPA was $(10 \mathrm{mM})$ added. The reaction mixture was incubated at $37^{\circ} \mathrm{C}$ for $5 \mathrm{~min}$. Red coloration resulting from dopachrome formation was observed and read spectrophotometrically at $475 \mathrm{~nm}$ (PG Instruments).

\section{Characterization of melanin pigment}

The cell free supernatant was collected from fermented broth by centrifugation at 10,000 $\mathrm{g}$ for $15 \mathrm{~min}$ (Eppendorf 5804 R). The supernatant was filtered through Whatman No.1 filter paper to remove residue cell debris. The initial purification of melanin was performed according to Wan et al. [20]. Briefly, the melanin supernatant was first adjusted to $\mathrm{pH} 9$ with $10 \mathrm{~N} \mathrm{NaOH}$ to ensure polymerization and then adjusted to $\mathrm{pH} 3$ with $5 \mathrm{~N} \mathrm{HCl}$ to precipitate melanin. The precipitated melanin was centrifuged, washed thrice with deionized water and lyophilized for further use. The absorbance spectrum of melanin produced by MSA10 was measured with UV/ VIS Spectrophotometer (PG instruments) over a range of wavelengths from 190 to $500 \mathrm{~nm}$. The color intensity of melanin was measured by CR- 300 colorimeter with the HunterLab color system. The L* (lightness ranges from 0-100 (dark - light)), a* (red- green) and b* (yellow-blue) values were determined. The lyophilized melanin pigment was spotted on the TLC plate and the chromatogram was performed with the solvent system n-butanol: acetic acid: water (70:20:10). After drying, the pigment spot was sprayed with ninhydrin. The TLC purified pigment were applied to a column of DEAECellulose (Bio-Rad, $1 \times 30 \mathrm{~cm}$ ) that had been equilibrated with $25 \mathrm{mM}$ Tris- $\mathrm{HCl}$ buffer (pH 8.6) containing $50 \mathrm{mM}$ sodium chloride. The column was eluted at a flow rate of $100 \mathrm{ml} / \mathrm{h}$ with 1:1 volume gradient from $0.1 \mathrm{M}$ to $2 \mathrm{M} \mathrm{NaCl}$ in the same buffer.

\section{Physico-chemical properties of the melanin}

The physico - chemical properties of Nocardiopsis melanin was analyzed according to Wang et al. [21]. The solubility of purified melanin was checked by adding $0.05 \mathrm{~g}$ of the melanin in $10 \mathrm{ml}$ of water, aqueous acid, alkali (such as $\mathrm{Na}_{2} \mathrm{CO}_{3}, \mathrm{NaOH}$ solution), and organic solvents such as chloroform, ethyl acetate, ethanol, methanol, acetic acid, petroleum ether, hexane with stirring at $25^{\circ} \mathrm{C}$ for $1 \mathrm{~h}$, then filtered and the absorption of the solutions were recorded spectrophotometrically at $220 \mathrm{~nm}$. The temperature stability of melanin pigment was measured after treatment with various temperatures in a thermostatically controlled water bath at $20,40,60,80$ and $100^{\circ} \mathrm{C}$ for $3 \mathrm{~h}$ and subsequently the absorption of the solutions were recorded at $220 \mathrm{~nm}$. Light stability of melanin was detected by holding the melanin solution $(5 \mathrm{mg} / \mathrm{ml})$ under natural light, at dark place and under the Ultraviolet-light far from $30 \mathrm{~cm}$ for two days and every $12 \mathrm{~h}$ interval the maximum absorbance was measured at $220 \mathrm{~nm}$. The $\mathrm{pH}$ stability was assessed by adjusting the melanin solution $(5 \mathrm{mg} / \mathrm{ml})$ in to a varied $\mathrm{pH}$ range $(3,4,6,7,9,10$ and 12$)$ with $0.5 \mathrm{~N} \mathrm{NaOH}$ and $\mathrm{HCl}$. All the samples were held for $30 \mathrm{~min}$ at $25^{\circ} \mathrm{C}$, and the absorption spectrum (190$220 \mathrm{~nm}$ ) was scanned. 


\section{Determination of antioxidant activity and reducing power of melanin}

The antioxidant activity of Nocardiopsis melanin was determined by a standard spectroscopic method [52]. Briefly, Aliquots of $2 \mathrm{ml}$ of different concentration of melanin solution $(0.5,1$ and $1.5 \mathrm{mg} / \mathrm{ml})$ prepared in phosphate buffer $(0.2 \mathrm{M}, \mathrm{pH} 6.6)$ and mixed with $2 \mathrm{ml}$ of reagent solution ( $0.6 \mathrm{M}$ sulfuric acid, $28 \mathrm{mM}$ sodium phosphate, and $4 \mathrm{mM}$ ammonium molybdate). The tubes were capped and incubated in a thermal block at $95^{\circ} \mathrm{C}$ for $120 \mathrm{~min}$. Every $30 \mathrm{~min}$ the absorbance of the mixture was measured at $695 \mathrm{~nm}$ against a blank.

The reducing power of the melanin pigment was determined by standard method [53]. Briefly, different concentrations of melanin were mixed with phosphate buffer (2.5 ml, $0.2 \mathrm{M}, \mathrm{pH} 6.6)$ and potassium ferricyanide $\left[\mathrm{K}_{3} \mathrm{Fe}(\mathrm{CN})_{6}\right](2.5 \mathrm{ml}, 1 \%)$. The mixture was incubated at $50^{\circ} \mathrm{C}$ for $20 \mathrm{~min} .2 .5 \mathrm{ml}$ of TCA $(10 \%)$ was added to the mixture, which was then centrifuged at $3000 \mathrm{rpm}$ for $10 \mathrm{~min}$. The supernatant $(1.0 \mathrm{ml})$ was mixed with distilled water $(7.0 \mathrm{ml})$ and $\mathrm{FeCl}_{3}(0.5 \mathrm{ml}, 0.1 \%)$, and the absorbance was measured at $700 \mathrm{~nm}$. The Butylated hydroxytoluene (BHT in ethanol solution) was used as the standard and the obtained value was used to compare and interpret the result with melanin.

\section{Synthesis of melanin mediated nanostructures by boiling method}

Silver nanostructures were synthesized in vitro by adding $10 \mathrm{ml}$ purified melanin solution $(20 \mu \mathrm{g} / \mathrm{ml})$ to $40 \mathrm{ml}$ of $1 \mathrm{mM} \mathrm{AgNO}_{3}$ (Sigma) and vigorously stirred for 5 minutes. The mixture was incubated at $60^{\circ} \mathrm{C}$ for $30 \mathrm{~min}$. Both melanin and $\mathrm{AgNO}_{3}$ was maintained separately as control. Silver nanostructures synthesis at different temperature range from $40-100^{\circ} \mathrm{C}$ and different time intervals (0- $30 \mathrm{~min}$ ) were studied at $1 \mathrm{mM} \mathrm{AgNO}_{3}$. Then the nanostructures were characterized by UV-vis spectrophotometer (PG instruments), FT-IR spectrum (Spectrum RX1) and TEM analysis. TEM measurements were performed on a TECHNAI 10 PHILIPS model instrument operating at an accelerating voltage of $80 \mathrm{kV}$.

\section{Antimicrobial assay of melanin and silver nanostructures against food pathogens}

The silver nanostructures and the column purified melanin compound were tested for antimicrobial activity using well diffusion method and the area of the halo was measured [54]. The synthesized nanostructures were tested against common food pathogens such as Bacillus subtilis (MTCC 1305), Bacillus cereus (MTCC 1307), Staphylococcus aureus (MTCC 2940), Escherichia coli (MTCC 739), Vibrio cholerae (MTCC 3906), Vibrio parahaemolyticus (MTCC 451), Vibrio vulnificus (MTCC 1145), Pseudomonas fragi (MTCC 2458) and Salmonella typhi (MTCC 734). These were cultured on Muller Hinton agar (Himedia). Well was made with a sterile steel cork borer (1 $\mathrm{cm}$ diameter) and $50 \mu \mathrm{l}$ of purified melanin and silver nanostructures were added in the wells, incubated at $30^{\circ} \mathrm{C}$ for $24 \mathrm{~h}$. After incubation the clear halo was measured and the area of inhibition in $\mathrm{mm}^{2}$ was calculated.

\section{Abbreviations}

MSA: Marine sponge associated actinobacteria; UPGMA

algorithm: Unweighted pair group method with arithmetic mean algorithm; RDP-II: Ribosomal database project; ANOVA: Analysis of variance; TLC: Thin layer chromatography; UV- visible spectrum: Ultra violet - visible spectrum; FT-IR: Fourier transform infrared; BHT: Butylated hydroxytoluene; TEM: Transmission electron microscopy; OD: Optical density; RSM: Response surface methodology.

\section{Competing interests}

The authors declare that they have no competing interests.

\section{Authors' contributions}

DA and ANL performed the experiments and GSK wrote the manuscript. MVA and NAA set the rationale of the experiments. JS designed the study and helped for preparing the manuscript. All authors read and approved the final manuscript.

\section{Acknowledgements}

ANL is thankful to DBT for Junior Research Fellowship. GSK thankful to DST for Young Scientist Fellowship. DA is thankful to DST for INSPIRE fellowship. JS is thankful to DBT for research grant. (No BT/PR14678/AAQ/03/538/2010). Thank Addiriyah Chair for Environmental Studies, Department of Botany and Microbiology, College of Science, King Saud University, Saudi Arabia for their support.

\section{Author details}

'Department of Food Science and Technology, Pondicherry University, Puducherry 605014, India. ${ }^{2}$ Department of Microbiology, Bharathidasan University, Tiruchirappalli 620 024, India. ${ }^{3}$ Department of Microbiology, Pondicherry University, Puducherry 605014 , India. ${ }^{4}$ Department of Botany and Microbiology, Addiriyah Chair for Environmental Studies, College of Science, King Saud University, P. O. Box 2455, Riyadh 11451, Saudi Arabia.

Received: 9 July 2013 Accepted: 26 August 2013

Published: 1 May 2014

\section{References}

1. Kampman Y, de Clerck E, Kohn S, Patchala DK, Langerok R, Kreyenschmidt J: Study of the antimicrobial effect of silver-containing inner liners in refrigerators. Appl Microbiol 2008, 104:1808-1814.

2. Quintavalla S, Vicini L: Antimicrobial food packaging in meat industry. Meat Sci 2002, 62:373.

3. Appendini P, Hotchkiss $\mathrm{JH}$ : Review of antimicrobial food packaging. Innov Food Sci Emerg Technol 2002, 3:113-126.

4. U.S. Food and Drug Administration: FDA approved Food Contact Substances. http://www.fda.gov.

5. Fernandez A, Picouet P, Lloret E: Cellulose-silver nanoparticle hybrid materials to control spoilage-related microflora in absorbent pads located in trays of fresh-cut melon. Int J Food Microbiol 2010, 142:222-228.

6. Fayaz AM, Balaji K, Girilal M, Kalaichelvant PT, Venkatesan R: Mycobased synthesis of silver nanoparticles and their incorporation into sodium alginate films for vegetable and fruit preservation. J Agric Food Chem 2009, 57:6246-6252

7. Emamifar A, Kadivar M, Shahedi M, Soleimanian ZS: Evaluation of nanocomposite packaging containing $\mathrm{Ag}$ and $\mathrm{ZnO}$ on shelf life of fresh orange juice. Innov Food Sci Emerg Technol 2010, 11:742-748.

8. Zhou L, LV S, He G, He Q, Shi B: Effect of PE/Ag2O nano-packaging on the quality of apple slices. J Food Qual 2011, 34:171-176.

9. de Azeredo HMC: Antimicrobial nanostructures in food packaging. Trends Food Sci Tech 2013, 30:56-69.

10. Rozenberg BA, Tenne R: Polymer-assisted fabrication of nanoparticles and nanocomposites. Prog Polym Sci 2008, 33:40-112. 
11. Bajpai SK, Mohan YM, Bajpai M, Tankhiwale R, Thomas V: Synthesis of polymer stabilized silver and gold nanostructures. J Nanosci Nanotechnol 2007, 7:2994-3010

12. Zhang W, Qiao X, Chen J, Wang H: Preparation of silver nanoparticles in water-in-oil AOT reverse micelles. J Colloid Interface Sci 2006, 302:370-373.

13. Kiran G, Sabu A, Selvin J: Synthesis of silver nanoparticles by glycolipid biosurfactant produced from marine Brevibacterium casei MSA19. J Biotech 2010, 148:221-225.

14. Apte M, Girme G, Bankar A, RaviKumar A, Zinjarde S: 3, 4-dihydroxyL-phenylalanine-derived melanin from Yarrowia lipolytica mediates the synthesis of silver and gold nanostructures. J Nanobiotechnol 2013, 11:2.

15. Kim JK, Park SM, Lee SJ: Novel antimutagenic pigment produced by Bacillus licheniformis SSA3. J Microbiol Biotechnol 1995, 5:48-50.

16. Unagul P, Wongsa P, Kittakoop P, Intamas S, Srikiti-Kulchai P, Tanticharoen M: Production of red pigments by the insect pathogenic fungus Cordyceps unilateralis BCC 1869. J Ind Microbiol Biotechnol 2005, 32:135-140.

17. Riley PA: Melanin. Int J Biochem Cell Biol 1997, 29:1235-1239.

18. Langfelder K, Streibel M, Jahn B, Haase G, Brakhage AA: Biosynthesis of fungal melanins and their importance for human pathogenic fungi. Fungal Genet Biol 2003, 38:143-158.

19. Nappi A, Ottaviani E: Cytotoxicity and cytotoxic molecules in invertebrates. Bio Essays 2000, 22:469-480.

20. Jacobson ES: Pathogenic roles for fungal melanins. Clin Microbiol Rev 2000, 13:708-717.

21. Wan X, Liu HM, Liao Y, Su Y, Geng J, Yang MY, Chen XD, Shen P: Isolation of a novel strain of Aeromonas media producing high levels of dopa-melanin and assessment of the photoprotective role of the melanin in bio-insecticide applications. J App/ Microbio/ 2007, 103:2533-2541.

22. Wang Y, Casadevall A: Decreased susceptibility of melanized Cryptococcus neoformans to the fungicidal effects of ultraviolet light. Appl Environ Microbiol 1994, 60:3864-3866.

23. Nappi AJ, Christensen MG: Melanogenesis and associated cytotoxic reactions: applications to insect innate immunity. Insect Biochem Mol Biol 2005, 35:443-459.

24. Selvin J: Exploring the antagonistic producer Streptomyces MSI051: Implications of polyketide synthase gene type II and a ubiquitous defense enzyme phospholipase A2 in host sponge Dendrilla nigra. Curr Microbiol 2009, 58:459-463.

25. Lam KS: Discovery of novel metabolites from marine Actinomycetes. Curr Op Microbiol 2006, 9:245-251.

26. Gandhimathi R, Kiran GS, Hema TA, Selvin J, Rajeetha Raviji T, Shanmughapriya S: Production and characterization of lipopeptide biosurfactant by a sponge-associated marine actinomycetes Nocardiopsis alba MSA10. Bioprocess Biosyst Eng 2009, 32:825-835.

27. Aghajanyan A, Hambardzumyan A, Hovsepyan A, Asaturian R, Vardanyan A Saghiyan A: Isolation, purification and physicochemical characterization of water soluble Bacillus thuringiensis melanin. Pigment Cell research 2005, 18:130-135.

28. Wang HS, Pan YM, Tang XJ, Huang ZQ: Isolation and characterization of melanin from Osmanthus fragrans' seeds. LWT-Food Sci Technol 2006 39:496-502.

29. Huang S, Pan Y, Gan D, Ouyang X, Tang S, Ekunwe SIN, Wang H: Antioxidant activities and UV-protective properties of melanin from the berry of Cinnamomum burmannii and Osmanthus fragrans. Med Chem Res 2011, 20:475-481.

30. Chung YC, Chang CT, Chao WW, Lin CF, Chou ST: Antioxidative activity and safety of the $50 \%$ ethanolic extract from red bean fermented by Bacillus subtilis. IMR-NK1. J Agric Food Chem 2002, 50:2454-2458.

31. Dharmaraj S, Ashokkumar B, Dhevendaran K: Food-grade pigments from Streptomyces sp. isolated from the marine sponge Callyspongia diffusa. Food Research International 2009, 42:487-492.

32. Williams ST, Goodfellow M, Alderson G, Wellington EMH, Sneath PHA, Sackin MJ: Numerical classification of Streptomyces and related genera. J Gen Microbiol 1983, 129:1743-1813.

33. Huber M, Hintermann G, Lerch K: Primary structure of tyrosinase from Streptomyces glaucescens. Biochem 1985, 24:6038-6044.

34. Kawamoto S, Nakamura M, Yashima S: Cloning, sequence and expression of the tyrosinase gene from Streptomyces lavendulae MA406 A-1. J Ferment Bioeng 1993, 76:345-355.
35. Denova CD, Skinner DD, Morgenstern MR: A Streptomyces avermitilis gene encoding 4-hydroxyphenylpyruvic acid dioxygenase-like protein that directs the production of homogentisic acid and orchronotic pigment in Escherichia coli. J Bacteriol 1994, 176:5312-5319.

36. Goodwin PH, Sopher CR: Brown pigmentation of Xanthomonas campestris pv phaseoli associated with homogentisic acid. J Microbiol 1994, 40:28-34.

37. Fuqua WC, Weiner RM: The melA gene is essential for melanin biosynthesis in the marine bacterium Shewanella colwelliana. J Gen Microbiol 1993, 139:1105-1114.

38. Ruzafa C, Sanchezamat A, Solano F: Characterization of the melanogenic system in Vibrio cholerae ATCC 14035. Pigment Cell Res 1995, 8:147-152

39. Cho YJ, Park JP, Hwang HJ, Kim SW, Choi JW, Yun JW: Production of red pigment by submerged culture of Paecilomyces sinclairii. Lett Appl Microbiol 2002, 35:195-202

40. Pongrawee N, Saisamorn L: Improving solid- state fermentation of Monascus purpureus on agricultural products for pigment production. Food Bioprocess Technol 2009, 4:1384-1390.

41. Lin CF, Suen SJT: Isolation of hyper pigment productive mutants of Monascus sp. F-2. J Ferment Tech 1973, 51:757-759.

42. Babitha S, Julio C, Scowl CR, Pandey A: Effect of light on growth, pigment production and culture morphology of Monascus purpureus in solid - state fermentation. Word J Microbiol Biotehnol 2008, 24:2671-2675.

43. Zhang J, Cai J, Deng Y, Chen Y, Ren G: Characterization of melanin produced by a wild-type strain of Bacillus cereus. Front Biol 2007, 2:26-29.

44. Schmaler-Ripcke J, Sugareva V, Gebhardt P, Winkler R, Kniemeyer O, Heinekamp T, Brakhage AA: Production of pyomelanin, a second type of melanin, via the tyrosine degradation pathway in Aspergillus fumigatus. Appl Environ Microbiol 2009, 75:493-503.

45. Huang J, Li Q, Sun D, Lu Y, Su Y, Yang X, Wanh H, Wang Y, Shao W, He N, Hong J, Chen C: Biosynthesis of silver and gold nanoparticles by novel sun dried Cinnamomum canphora leaf. Nanotech 2007, 18:1-11.

46. Bowness JM, Morton RA: The association of zinc and other metals with melanin and a melanin-protein complex. J Biochem 1953, 53:620-626.

47. Geng J, Yuan P, Shao C, Yu SB, Zhou B, Zhou P, Chen XD: Bacterial melanin interacts with double-stranded DNA with high affinity and may inhibit cell metabolism in vivo. Arch Microbiol 2010, 192:321-329.

48. Karpilov A: Nanomaterials in food packaging: promise and potential peril. http://www.iopp.org/files/public/RITkarpilovIPTAsubmission.pdf.

49. Nanomaterials in food packaging: keeping food fresh for longer, less waste European Commission's Joint Research Centre, Institute for Health and Consumer Protection. http://ihcp.jrc.ec.europa.eu/our_activities/ nanotechnology/Nano_Food

50. Selvin J, Thangavelu T, Kiran GS, Gandhimathi R, Shanmughapriya S: Culturable heterotrophic bacteria from the marine sponge Dendrilla nigra: isolation and phylogenetic diversity of actinobacteria. Helgoland Mar Res 2009, 63:239-247.

51. Arai T, Mikami Y: Chromogenecity of streptomyces. Appl Microbiol 1972, 23:402-406

52. Prieto P, Pineda M, Miguel A: Spectrophotometric quantitation of antioxidant capacity through the formation of a phosphomolybdenum complex: specific application to the determination of vitamin E1. Anal Biochem 1999, 269:337-341.

53. Oyaizu M: Studies on product of browning reaction prepared from glucose amine. Jpn J Nutr 1986, 44:307-315

54. Cappuccino JG, Sherman N: Microbiology - a laboratory manual. 4th edition. Harlow, England: Addison Wesley Longman, Inc; 1999:199-204.

doi:10.1186/1477-3155-12-18

Cite this article as: Kiran et al: Melanin-templated rapid synthesis of silver nanostructures. Journal of Nanobiotechnology 2014 12:18. 